\title{
The impact of cancer therapy on the endocrine system in survivors of childhood brain tumours
}

\author{
HK Gleeson and S M Shalet
}

Department of Endocrinology, Christie Hospital, Manchester M20 4BX, UK

(Requests for offprints should be addressed to H K Gleeson; Email: Helena.Gleeson@christie-tr.nwest.nhs.uk)

\begin{abstract}
Survival rates are improving following cancer therapy for childhood brain tumours. There is therefore a growing cohort of survivors at risk of late effects of cancer therapy. Endocrine problems are very common in these patients. The recognition and prompt management of these are essential to prevent further morbidity and impairment of quality of life.

Cranial radiation can damage hypothalamic-pituitary function, most frequently affecting GH status; however, higher radiation doses may cause more widespread hypothalamic-pituitary damage. Early puberty secondary to cranial irradiation is now being managed with gonadotrophin-releasing hormone analogues to improve final height. Prompt diagnosis and management of GH deficiency may improve final height outcome; continued GH therapy beyond final height aids the achievement of adult body composition (lean body mass and bone mass) and GH therapy in adulthood improves quality of life. Both cranial irradiation alone and with spinal irradiation can result in radiation damage to the thyroid resulting in hypothyroidism and thyroid nodules, a high proportion of which are malignant. Gonadal damage secondary to spinal irradiation and adjuvant chemotherapy may have long-term consequences including infertility.
\end{abstract}

Endocrine-Related Cancer (2004) 11 589-602

\section{Introduction}

Brain tumours are the most common type of solid neoplasms that occur in children (Gurney et al. 1996). Survival after a diagnosis of a malignant brain tumour has improved substantially over the last few decades. The 5 -year relative survival probability for all brain malignancies combined for children is approximately 65\% (de Nully Brown et al. 1995, Bleyer 1999, Ries et al. 2003). However, the improvement in prognosis has been achieved at the cost of serious late effects. Survivors of childhood brain tumours are at a high risk of adverse medical, neurocognitive and psychosocial late effects (Anderson et al. 2001). Endocrine disorders are prominent among the spectrum of long-term conditions that may afflict brain tumour survivors; in one survey $43 \%$ had a self-reported endocrine condition (Gurney et al. 2003b). These may impact negatively on growth, body composition, fertility, quality of life, morbidity and mortality.

\section{Hypothalamic-pituitary axis}

\section{Role of radiation}

Neuroendocrine abnormalities may follow cranial irradiation resulting in deficiency of one or more anterior pituitary hormones. The radiobiological impact of a radiation schedule depends on the total dose, fraction size, number of fractions and the duration.

There is a strong correlation between the total radiation dose and the development of pituitary hormone deficits (Shalet et al. 1976a, Duffner et al. 1985, Littley et al. 1989b, Clayton \& Shalet 1991b, Constine et al. 1993). Thus, after lower radiation doses, as used in the treatment of acute lymphoblastic leukaemia (ALL) or brain tumours (18-50 Gy), isolated growth hormone deficiency (GHD) occurs, while higher doses ( $>60 \mathrm{~Gy}$ ) may produce panhypopituitarism. Interestingly, however, diabetes insipidus is not seen following irradiation to the hypothalamic- 
pituitary axis. Also the same total dose given in fewer fractions over a shorter time period is likely to cause a greater incidence of pituitary hormone deficiency than if the schedule is spread over a longer time interval with a greater number of fractions (Shalet et al. 1976b).

More recently, the degree of anterior pituitary hormone deficit has been correlated with the biological effective dose (BED) of radiation affecting the hypothalamic-pituitary axis. The formula used to calculate the BED incorporates total dose, fraction size and tissue response to radiation (Schmiegelow et al. 2000). Calculation of the BED provides a useful method of comparing radiation schedules and predicting the effect on hypothalamic-pituitary function (Schmiegelow et al. 2000).

The hypothalamus is more radiosensitive and is damaged by lower doses of cranial radiation than the pituitary. Thus, after lower doses of cranial irradiation $(<50 \mathrm{~Gy})$ the primary site of radiation damage is hypothalamic, and is usually associated with isolated GHD (Samaan et al. 1975, Chrousos et al. 1982, Ahmed et al. 1986, Lannering \& Albertsson-Wikland 1987, Costin 1988), whereas higher doses may also produce direct anterior pituitary damage which contributes to early and multiple pituitary hormone deficiencies (Samaan et al. 1975, 1982).

Hypothalamic-pituitary dysfunction secondary to radiation is also time dependent. There is an increase in the frequency and severity of hormonal deficits with a longer time interval after radiotherapy. The progressive nature of the hormonal deficits following radiation damage to the hypothalamic-pituitary axis can be attributed to the delayed effects of radiotherapy on the axis or the development of secondary pituitary atrophy following previous hypothalamic damage (Spoudeas et al. 1996, Clayton \& Shalet 1991b, Schmiegelow et al. 2000). This necessitates prolonged follow-up with yearly testing of pituitary function in patients treated with cranial irradiation for brain tumours.

The damaging effects of radiation on hypothalamicpituitary axis function are also increased when the hypothalamic-pituitary axis is already affected by another pathology. A radiation dose of $35-42.5 \mathrm{~Gy}$ to the hypothalamic-pituitary axis caused isolated GHD in the majority of children treated for non-pituitary brain tumours (Shalet et al. 1975, Duffner et al. 1985), whereas a similar dose in adult patients irradiated for pituitary adenomas led to multiple pituitary hormone deficits in more than $80 \%$ within a similar time scale after radiotherapy (Littley et al. 1989c).

The difference in the development of the anterior pituitary hormone deficiencies, with growth hormone (GH) being most frequently affected, suggests that selective hypothalamic neuronal and pituitary cell damage by direct radiation occurs. Consequently, while GHD is prevalent in brain tumour survivors, other pituitary hormone deficits occurred in only $2-6 \%$ after almost 10 years following 40-50 Gy (Shalet et al. 1977, Livesey et al. 1990). Clinical observations reveal that GH is the most radiosensitive followed by gonadotrophin and adrenocorticotrophin (ACTH) with thyrotrophin (TSH) the last hormone to be affected, although variations in this order can occur.

Whether or not the age of the patient at the time of radiotherapy is an additional factor that determines the extent of radiation damage sustained by the hypothalamic-pituitary axis is unknown. Some but not all data suggest that children are more radiosensitive than adults and that older children are less vulnerable than younger children to the risk of developing GHD following radiation to the hypothalamic-pituitary axis (Shalet et al. 1976a).

There have been reports that suggest that chemotherapy potentiates the deleterious effect of radiation on pituitary function (Spoudeas et al. 1996, Achermann et al. 1998, Gleeson et al. 2004). There is no conclusive evidence to date, however, that chemotherapy alone results in neuroendocrine dysfunction.

\section{Growth hormone deficiency}

Current evidence suggests that nearly $100 \%$ of children treated with radiation doses in excess of $30 \mathrm{~Gy}$ will have blunted GH responses to an insulin tolerance test (ITT), whilst $35 \%$ of those receiving less than $30 \mathrm{~Gy}$ still show a normal peak GH response to the ITT between 2 and 5 years after radiotherapy (Clayton \& Shalet 1991b). Prospective studies also suggest that impaired GH responses to provocative tests can occur as early as 3 months and certainly in the first 12 months postirradiation for brain tumours (Shalet et al. 1975, Duffner et al. 1985).

Radiation-induced GH neurosecretory dysfunction is well described following radiation injury to the hypothalamic-pituitary axis (Chrousos et al. 1982, Blatt et al. 1984, Spoudeas et al. 1996). It is characterised by diminished spontaneous (physiological) GH secretion in the presence of preserved peak $\mathrm{GH}$ responses to provocative tests (Bercu \& Diamond 1986). Thus, the reported frequency of radiation-induced GHD is likely to be influenced by the type of investigation used to assess $\mathrm{GH}$ secretion, i.e. physiological versus pharmacological tests. Most prospective studies have concentrated on provocative tests and therefore the exact prevalence of radiation-induced GHD may well be underestimated. For example, Albertsson-Wikland et al. (1987) showed that spontaneous $\mathrm{GH}$ secretion was severely disturbed in all children more than 2 years after they had received cranial 
irradiation ( $>40 \mathrm{~Gy}$ ) for brain tumours. This is in contrast to the lower incidence of GHD with the same radiation schedules and time scale reported in other studies which relied on stimulation tests. The discrepancy between stimulated and spontaneous GH secretion tends to disappear with time after radiotherapy and it is likely that patients who develop impaired $\mathrm{GH}$ responses to provocative tests late after irradiation may have had GH neurosecretory dysfunction at an earlier stage (Darzy et al. 2003). Further studies are needed to define the exact incidence of radiation-induced $\mathrm{GH}$ neurosecretory dysfunction in children and its clinical relevance.

\section{Abnormalities of gonadotrophin secretion}

The effect of cranial irradiation on the hypothalamicpituitary-gonadal axis is dose dependent. Doses in excess of $50 \mathrm{~Gy}$ may render a child gonadotrophin deficient whereas lower doses, paradoxically, may result in early puberty.

\section{Early puberty}

The mechanism for early puberty following irradiation is thought to be due to the disinhibition of cortical influences on the hypothalamus. Puberty then proceeds through the increased frequency and amplitude of gonadotrophinreleasing hormone $(\mathrm{GnRH})$ pulsatile secretion by the hypothalamus (Roth et al. 2000, 2001).

Low-dose cranial irradiation employed in central nervous system prophylaxis for ALL is associated with a higher incidence of early puberty, which predominantly affects girls (Leiper et al. 1987). At higher radiation doses employed in the treatment of brain tumours (25-50 Gy) early puberty is not restricted to girls. Ogilvy-Stuart et al. (1994) demonstrated that in 46 GHD children previously irradiated for brain tumours $(25-47.5 \mathrm{~Gy})$ the onset of puberty occurred at an early age in both sexes and there was a significant linear association between age at irradiation and age at onset of puberty, i.e. the younger the age at irradiation the earlier the onset of puberty (Fig. 1). Subsequently Lannering et al. (1997) also showed that boys who received high doses of irradiation for brain tumours entered puberty at a median age of 10.5 years compared with an average age for Swedish boys of 12.4 years; again emphasising the disappearance of sexual dichotomy with higher radiation doses.

\section{Gonadotrophin deficiency}

When the dose of cranial irradiation exceeds $50 \mathrm{~Gy}$ in the treatment of brain tumours there is a progressive increase in the incidence of gonadotrophin deficiency. Rappaport et al. (1982) reported that 14 out of 45 children studied

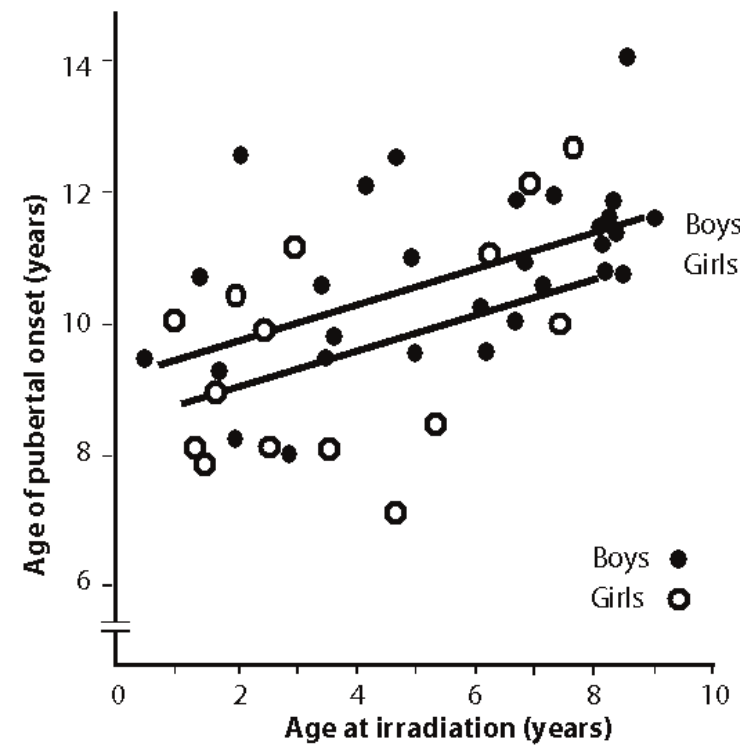

Figure 1 Age at onset of puberty compared with age at irradiation in children treated for brain tumours (Ogilvy-Stuart et al. 1994).

following high-dose cranial irradiation for head and neck tumours showed evidence of partial or severe gonadotrophin deficiency. The prevalence of gonadotrophin deficiency also increases with time post-irradiation, a cumulative incidence of $20-50 \%$ has been reported in patients followed long term, making it the second most common anterior pituitary hormone deficit in many series (Rappaport et al. 1982, Constine et al. 1993).

Gonadotrophin deficiency exists in a range of severity from subtle (subclinical) abnormalities with low normal sex hormone levels to severe impairment associated with subnormal circulating sex hormone levels.

In a study of 30 male survivors of childhood brain tumours who had received 40-60 Gy of cranial irradiation, there was evidence of subtle secondary hypogonadism compared with age-matched normal controls after a median of 18 years follow-up (Schmiegelow et al. 2001).

\section{ACTH deficiency}

A recent study of 73 patients who were treated with cranial irradiation for childhood brain tumours not directly involving the hypothalamic-pituitary axis observed that $19 \%$ had abnormalities of the hypothalamic-pituitary-adrenal axis after 15 years of follow-up (Schmiegelow et al. 2003b). Previous studies all based on less than 12 years follow-up demonstrated only subtle abnormalities (Livesey et al. 1990, Constine et al. 1993, Oberfield et al. 1997, Spoudeas et al. 2003) suggesting that the hypothalamic-pituitary-adrenal axis might be 
affected relatively late by irradiation. This was further illustrated in the same study by the relationship between the length of follow-up and the peak cortisol response to an ITT (Schmiegelow et al. 2003b). Longer follow-up data beyond 15 years in these patients is not available.

Dose of irradiation is important as no damage to the hypothalamic-pituitary-adrenal axis was reported following lower doses of irradiation (18-24 Gy) in the treatment of ALL after 3.6 to 10 years of follow-up (Crowne et al. 1993) compared with the higher doses of radiation used in the treatment of brain tumours when subtle abnormalities were identified after a similar period of follow-up (Livesey et al. 1990, Constine et al. 1993, Oberfield et al. 1997). The dose-response relationship was confirmed by the recent follow-up study in brain tumour survivors (Schmiegelow et al. 2003b).

The manner in which ACTH deficiency is diagnosed in this irradiated cohort is important. The ITT is considered the gold standard; however, it is contraindicated in patients with a history of fits which immediately excludes a proportion of brain tumour survivors. Many centres are also reluctant to perform ITTs at all because of lack of experience and/or suitable levels of supervision. Consequently, many centres employ the well-tolerated glucagon stimulation test (GST) (Leong et al. 2001) which allows the assessment of both GH and ACTH reserve. Although compared with the ITT the GST evokes a less pronounced GH response, the cortisol responses to the two tests in healthy individuals (Littley et al. 1989a) and patients with pituitary disease (Orme et al. 1996) appear to be comparable in magnitude.

The short synacthen test (SST) is extensively used in clinical practice; there is, however, controversy surrounding the use of the SST in assessing ACTH deficiency particularly in situations where partial ACTH deficiency may occur, as may be the case following cranial irradiation. Of the 33 patients who had both an SST and an ITT, ten patients had discordant results, i.e. failing the ITT but passing the SST; however, eight of the ten had a peak cortisol between 400 and $500 \mathrm{nmol} / 1$ to an ITT (Schmiegelow et al. 2003b). This is suggestive of partial ACTH deficiency, the implications of which are likely to be less critical than for a patient with severe ACTH deficiency.

In summary, an awareness of ACTH deficiency in brain tumour survivors is essential and monitoring should continue beyond 10 years following irradiation. If reliance is placed on a test other than an ITT, for instance as SST, caution should be maintained in a patient diagnosed as ACTH sufficient following cranial irradiation.

\section{TSH deficiency}

The hypothalamic-pituitary-thyroid axis appears to be the least vulnerable to radiation damage. The frequency of radiation-induced TSH deficiency has been clearly shown to be dose related (Constine et al. 1993) and also related to the length of time from irradiation (Schmiegelow et al. 2003a).

Making the diagnosis of central hypothyroidism is important but notoriously difficult. Most clinicians rely on basal thyroid function tests (TFTs; TSH and thyroxine (T4)), making the diagnosis when there is a low normal or subnormal T4 level, particularly if there is evidence of declining T4 levels over time, with a low, normal or mildly raised TSH level with or without symptoms of hypothyroidism.

A survey of 71 childhood brain tumour survivors assessed after a median of 12 years of follow-up using baseline TFTs found that only $6 \%$ had evidence of central hypothyroidism (Schmiegelow et al. 2003a). This is in keeping with previous studies (Livesey \& Brook 1989, Oberfield et al. 1992). However, another study controversially claimed that the reason TSH deficiency is reported to be the last anterior pituitary hormone to become deficient is due to the insensitivity of baseline TFTs in making the diagnosis and the authors claim that the thyrotrophin-releasing hormone (TRH) test and the presence or absence of a nocturnal TSH surge are more useful diagnostically (Rose et al. 1999). This study (Rose et al. 1999) examined 208 childhood cancer survivors after a mean of 6 years follow-up and diagnosed $36 \%$ as having evidence of hidden central hypothyroidism; however, $20 \%$ of the children with non-cranial tumours, who had not received any form of cranial irradiation, had evidence of central hypothyroidism at 5 years and $16 \%$ of those with central hypothyroidism had received only chemotherapy. This places huge doubt over the specificity of the TRH test and/or an absent TSH surge to diagnose central hypothyroidism in the presence of a normal T4 level.

\section{Endocrine target organs Primary gonadal failure}

In brain tumour survivors gonadal damage most frequently occurs secondary to adjuvant chemotherapy. Gonadotoxicity is dose dependent and can occur with the following chemotherapy agents: alkylating agents, procarbazine, cisplatin and vinblastine (Ahmed et al. 1983, Clayton et al. 1989). Scattered radiation from spinal radiotherapy may also be responsible for gonadal damage (Livesey \& Brook 1988, Ahmed et al. 1983, Schmiegelow et al. 2001).

In females, sex steroid production and germ cells are lost in parallel. Loss of sex steroid production may manifest itself early as failure to enter or progress through puberty, or later with symptoms of premature menopause which may place the patient at risk of all the biological 
consequences of hypogonadism as well as problems with fertility. In one study of brain tumour survivors after 8 years follow-up, $64 \%$ (seven out of eleven) of girls who had received craniospinal irradiation without adjuvant chemotherapy had evidence of primary ovarian damage as determined by elevated gonadotrophins (Livesey \& Brook 1988). Another study found that it was only the adjuvant chemotherapy (in particular the alkylating agent, nitrosourea and procarbazine) in combination with craniospinal irradiation that resulted in primary ovarian failure (Ahmed et al. 1983).

In males, spermatogenesis is more sensitive to damage by cancer therapy than Leydig cell function, therefore men may be infertile yet have normal levels of testosterone. Scattered radiation from craniospinal irradiation itself has been reported not to damage Leydig cell function (Ahmed et al. 1983, Schmiegelow et al. 2001), whereas impaired spermatogenesis has been observed in brain tumour survivors secondary to chemotherapy alone and also in combination with spinal irradiation (Ahmed et al. 1983, Livesey \& Brook 1988, Schmiegelow et al. 2001).

\section{Primary thyroid damage}

The thyroid gland in children is among the most sensitive organ to damage by radiation. Hypothyroidism, thyroid nodules and hyperthyroidism have been described (Sklar et al. 2000). The role of chemotherapy is less clear.

Compensated or frank hypothyroidism has been described in $20-60 \%$ of brain tumour survivors depending on treatment modalities and length of follow-up (Livesey et al. 1990, Ogilvy-Stuart et al. 1991, Schmiegelow et al. 2003a). Damage can occur in the brain tumour survivor secondary to scattered radiation from craniospinal irradiation as well as from cranial irradiation alone (Schmiegelow et al. 2003a). Fraction size is also important as it has been observed that hyperfractionation with conventional spinal irradiation schedules results in less damage to the thyroid (Ricardi et al. 2001). An increased incidence of hypothyroidism has been observed with adjuvant chemotherapy in combination with irradiation compared with irradiation alone (Livesey \& Brook 1989, Ogilvy-Stuart et al. 1991, Paulino 2002). However, three recent studies have failed to confirm this finding (Chin et al. 1997, van Santen et al. 2003, Schmiegelow et al. 2003a).

Excess thyroid cancer has been reported following treatment for brain tumours (Goldstein et al. 1997). Thyroid nodules occur frequently in the irradiated population (Kaplan et al. 1983, Tucker et al. 1991). The percentage of nodules which contain malignancy in cancer survivors varies from $14 \%$ to $40 \%$ depending on the method of detection (Crom et al. 1997, Acharya et al. 2003). Very young children are at higher risk as are females. At low to moderate doses of radiation there is a linear relationship with risk of developing thyroid cancer which flattens out at higher doses (Ron et al. 1995). Radiation-induced tumours begin to appear 5-10 years after irradiation and excess risk persists for decades (Schneider et al. 1993). Most of the thyroid cancers are usually well-differentiated papillary carcinomas but follicular tumours also occur.

Clinical assessment has limitations in both detecting and characterising thyroid nodules, and can miss those smaller than $2 \mathrm{~cm}$ (Brander et al. 1992). Consequently some physicians advocate the use of ultrasound (Healy et al. 1996, Crom et al. 1997). However, the smaller thyroid nodules are less likely to be malignant and therefore the use of a more sensitive screening strategy may increase patient anxiety without necessarily improving outcome. Therefore the standard practice in many centres is to perform TFTs and thyroid gland palpation annually in brain tumour survivors. If the TSH is found to be only mildly raised, T4 replacement should be instituted as an elevated TSH is known to promote thyroid tumour growth. Thyroid cancer in survivors should be treated in a similar fashion to such tumours arising in the unirradiated patient. The disease-free interval or survival in patients treated for thyroid cancer is uninfluenced by whether or not there is a history of thyroid irradiation (Schneider et al. 1986).

\section{Obesity and cardiovascular risk}

Obesity is a recognised late effect in cancer survivors. Obesity is a risk factor for morbidity in the general population. It is therefore important to understand the pathogenesis of obesity in this group to treat and prevent further disability and early demise.

Lustig et al. (2003a), in a study of brain tumour survivors, identified hypothalamic damage from any source of treatment, but in particular radiation doses of $50 \mathrm{~Gy}$ or higher were associated with abnormal 10-year post-therapy body mass index (BMI) increases and therefore a primary risk factor for obesity. Young age at diagnosis was also identified as a risk factor (Lustig et al. 2003a), as has been identified in ALL survivors (Didi et al. 1995).

Damage to the hypothalamus is associated with obesity. The mechanism for this phenomenon has been postulated to be due to damage to the ventromedial hypothalamus (VMH) (Gold et al. 1972), which normally integrates the blood-borne information from the peripheral hormones leptin, ghrelin and insulin. The VMH translates this information into regulation of energy balance. Dysfunction of the VMH results in excessive caloric intake and decreased caloric expenditure, resulting 
in relentless weight gain (Schwartz et al. 2000). There are two hypotheses, one proposes that VMH damage results in hyperphagia, resultant obesity and compensatory hyperinsulinaemia, the other that VMH damage disinhibits the efferent output of the vagus nerve, which acts on the pancreatic $\beta$ cell to promote excessive insulin secretion. Lustig et al. (2000b) found that reducing the hyperinsulinaemia in 18 cancer survivors with hypothalamic damage by using octreotide resulted in a reduction of weight gain. Octreotide, the long-acting somatostatin analogue, binds to the somatostatin receptor 5 (SSTR5) on the $\beta$ cell and results in inhibition of intracellular calcium influx and attenuation of insulin release.

Children with brain tumours frequently receive highdose glucocorticoid treatment to either reduce symptoms of raised intracranial pressure or to limit post-operative oedema. Glucocorticoids could promote obesity by effects on appetite and regulation of energy intake, alterations in substrate oxidation and/or alteration in energy expenditure (Tataranni et al. 1996). However, studies in ALL survivors have been unable to conclusively demonstrate a link between weight gain and the dose of steroid used, probably because of small sample sizes (Van Dongen-Melman et al. 1995). The recent study by Lustig et al. (2003a) excluded patients who had received prolonged supraphysiological glucocorticoids.

Radiation to the hypothalamic-pituitary region results in hypopituitarism, with $\mathrm{GH}$ the most frequently affected hormone. GH is known to have numerous metabolic effects. When GHD is prolonged, affected individuals are at increased risk of obesity; GH therapy can help to reverse these effects (Salomon et al. 1989). In a study examining cardiovascular risk, an elevated systolic blood pressure, increased waist:hip ratio and an adverse lipid profile were more commonly seen in brain tumour survivors than normal controls and these abnormalities were particularly pronounced in those with untreated GHD (Heikens et al. 2000).

Intracranial tumours and their treatment are associated with neurological complications that may have adverse effects on motor function which may, in turn, result in significantly reduced physical activity, thus predisposing a child to obesity. Reduced physical activity has been shown to be common in patients treated for ALL both during and after therapy (Reilly et al. 1998, Warner et al. 1998).

Reassuringly, the Childhood Cancer Survivor Study has published results on self-reported BMI in patients treated for brain tumours and found that the BMI of survivors did not differ appreciably from that of sibling controls with only $15 \%$ having a BMI of greater than 30 (Gurney et al. 2003a).
There is only limited evidence on strategies for prevention or treatment of obesity in children with cancer (Gregory \& Reilly 2004). Clearly lifestyle advice on diet and exercise must be employed early; however, true 'hypothalamic' obesity may be resistant to these measures. Where possible, future more focal irradiation schedules for children with tumours in the posterior fossa and temporal lobes may reduce incidental hypothalamic irradiation. There may also be a role for controlling hyperinsulinaemia, for instance, by octreotide in the more severe cases but randomised controlled trials of efficacy are required (Gregory \& Reilly 2004).

\section{Growth and attainment of final height}

Suboptimal growth in brain tumour survivors is multifactorial in aetiology and may be a consequence of poor nutrition, tumour recurrence, impaired spinal growth due to spinal radiotherapy, chemotherapy, radiation-induced GHD, early puberty and other endocrinopathies.

The Childhood Cancer Survivor Study has published results on self-reported final height in patients with brain tumours and found that $40 \%$ were below the tenth percentile for height (Gurney et al. 2003a). There is a clear association between final height and age at diagnosis (Ogilvy-Stuart \& Shalet 1995, Helseth et al. 1999, Noorda et al. 2001, Gurney et al. 2003a, Xu et al. 2003). In this most recent study, children diagnosed before the age of 5 years were fivefold more likely to have adult short stature than children diagnosed after the age of 9 years (Gurney et al. $2003 a$ ). There is clear evidence that the degree of impairment of spinal growth is greater the younger the child (Shalet et al. 1987), and it is the young irradiated child who is at risk of early puberty. Finally, the possibility remains that the hypothalamic-pituitary axis of the young child is more radiosensitive than in older children.

\section{Spinal irradiation}

Spinal irradiation results in a reduction in sitting height resulting in an overall poor adult height (Shalet et al. 1987, Clayton \& Shalet 1991a). Spinal growth exceeds leg length growth during puberty and it is during this time that spinal growth is particularly impaired in those that have received craniospinal irradiation, resulting in an exaggeration of disproportion at final height. The effect on the spine is dependent on the dose of irradiation (Xu et al. 2003) and age at irradiation (Probert et al. 1973, Shalet et al. 1987).

\section{Chemotherapy}

Adjuvant chemotherapy has been reported to be associated with risk of short final height. It has been shown 
that growth in the first 4 years after treatment with craniospinal irradiation is more profoundly affected in children who have received adjuvant chemotherapy than in those receiving craniospinal irradiation alone, suggesting potentiation of radiation-induced growth failure by chemotherapy (Olshan et al. 1992). Ogilvy-Stuart \& Shalet (1995) demonstrated that the effect of chemotherapy on final height was as profound as craniospinal irradiation in GH-treated brain tumour survivors. It has been hypothesised that cytotoxic drugs may amplify the damage to the hypothalamic-pituitary axis by irradiation (Spoudeas et al. 1996), directly affect the production of insulin-like growth factor-I (IGF-I) by the liver (Nivot et al. 1994) and/or impair the action of IGF-I on the growth plate.

\section{Management of endocrine late effects Growth-promoting strategies}

Final height outcome is important in survivors of childhood brain tumours. GH replacement is indicated in those found to be GHD. More recently, GnRH analogues $(\mathrm{GnRH} a)$ have been introduced to delay early or rapidly progressing puberty to allow more time for linear growth. Studies to final height are important to determine the effectiveness of growth-promoting strategies.

\section{GH replacement}

There have been numerous studies of GH replacement in brain tumour survivors with GHD. Unfortunately, meaningful interpretation can be difficult because of the following weaknesses: assessment made before final height is achieved (Clarson \& Del Maestro 1999); small sample size; failure to consider familial determinants (Darendeliler et al. 1990); data collected from multiple centres introducing variations in oncology therapy, hormonal therapy and auxological assessments (Gurney et al. 2003a).

In 1995 our unit published final height data in 29 children who had received $\mathrm{GH}$ for radiation-induced GHD following therapy for brain tumours and clearly demonstrated the detrimental effect of spinal irradiation and the additive adverse effect of chemotherapy (OgilvyStuart \& Shalet 1995). We have recently revisited this topic and published final height data in the largest cohort of brain tumour survivors reported from a single centre (Gleeson et al. 2003). Because of the time span of the data collection we have been able to assess differences in practice over the last 25 years and have shown that, over this time, patients have come much closer to achieving target height (Fig. 2) (Gleeson et al. 2003).

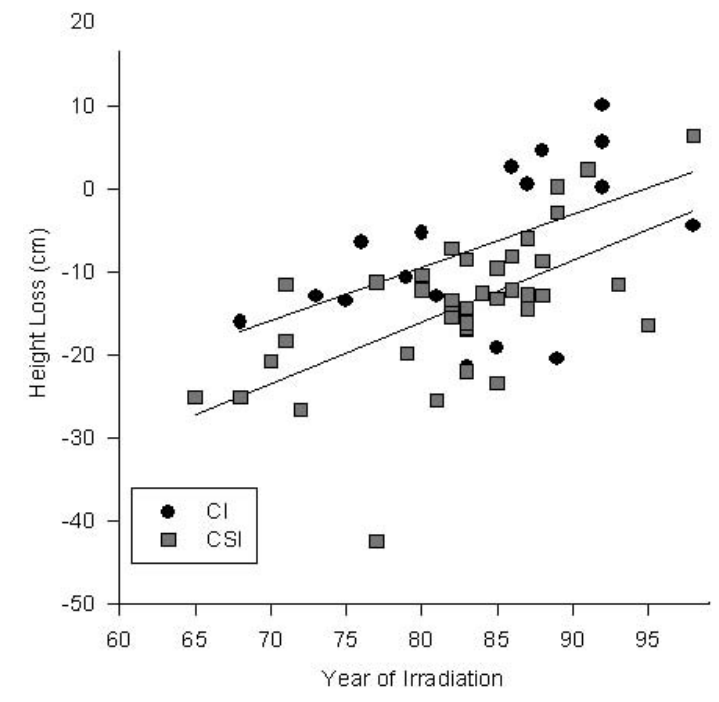

Figure 2 Improvements in height loss in children treated for brain tumours from 1975 to 2000 (Gleeson et al. 2003). Cl, cranial irradiation; CSI, craniospinal irradiation.

In this study (Gleeson et al. 2003), auxological outcomes were affected by age at irradiation. From the perspective of clinical management, age at irradiation was correlated with a longer period of time until first assessment of GH status and consequently a longer time until GH therapy was started. In addition, those children irradiated in the latter time period of the study (after 1988) were first assessed for GHD and started on GH therapy on average 2 years earlier after irradiation than those treated previously despite similar age at irradiation. This change in practice may, in part, explain the improvements in final height outcome. Reassuring safety data (Moshang et al. 1996, Swerdlow et al. 2000, Packer et al. 2001, Sklar et al. 2002) have allowed this earlier and bolder approach to $\mathrm{GH}$ replacement in cancer survivors.

Another reason for improvement in final height is the effect of the GH treatment protocol. Adan et al. (2000) commented that the final height results of a previous study using extracted $\mathrm{GH}$ given as $0.1 \mathrm{mg} / \mathrm{kg}$ intramuscular injections thrice weekly (Sulmont et al. 1990) were worse than the results that were achieved using daily subcutaneous injections of $\mathrm{GH}(0.2 \mathrm{mg} / \mathrm{kg}$ per week) (Adan et al. 2000). Another study using even higher doses of $\mathrm{GH}(0.3 \mathrm{mg} / \mathrm{kg}$ per week) claimed that their final height results in children treated with craniospinal irradiation were better than in earlier studies ( $\mathrm{Xu}$ et al. 2003). A recently reported dose-response study of GH in children with GHD demonstrated that a dose of $0.35 \mathrm{mg} / \mathrm{kg}$ per week significantly improved growth velocity over 2 years, compared with similarly affected children (Cohen et al. 2002) randomised to receive $0.15 \mathrm{mg} / \mathrm{kg}$ per week. Although to date the use of GH replacement in childhood 
cancer survivors has not been associated with increased tumour recurrence, there is a question mark over the possibility of an increased risk of secondary neoplasms that needs to be considered in future epidemiological studies (Moshang et al. 1996, Swerdlow et al. 2000, Packer et al. 2001, Sklar et al. 2002). Therefore, long-term safety needs always to be a consideration when using potentially supraphysiological doses of GH.

\section{GnRHa therapy}

The effect of GnRHa in children with precocious puberty without organic pathology is clear, with the results from numerous studies demonstrating an improvement in final height compared with untreated patients (Partsch \& Sippell 2002). However, there is little information about its impact on final height if used from early puberty onwards. Studies that have investigated the use of GnRHa to delay puberty in GHD children have reported that final height outcome is improved nearly to target height (Mul et al. 2001, Saggese et al. 2001, Mericq et al. 2002). Three studies have looked at the use of GnRHa for the treatment of early puberty in cancer survivors treated with GH for radiation-induced GHD (Adan et al. 2000, Gleeson et al. 2003, Xu et al. 2003).

In patients previously treated with cranial irradiation without spinal irradiation, improvement has been demonstrated in final height in those who received GnRHa. Adan et al. (2000) reported improvements in final height in 21 cancer survivors who had received cranial irradiation treated with GnRHa compared with a group of survivors who did not receive GnRHa. The groups, however, were not matched for diagnosis, age at irradiation, dose of irradiation or use of chemotherapy (Adan et al. 2000). In GH-replaced brain tumour survivors, Gleeson et al. (2003) compared the actual auxological outcome in 11 children (cranial irradiation $n=5$; craniospinal irradiation $n=6$ ) also treated with a GnRHa against the predicted auxological outcome without treatment with GnRHa and demonstrated significant improvements in final height outcome with the use of GnRHa in patients who had received cranial irradiation $(+18 \mathrm{~cm} ;+2.7$ standard deviation score $(\mathrm{SDS}))$ and to a lesser extent craniospinal irradiation $(+3.2 \mathrm{~cm} ;+0.9 \mathrm{SDS})$. Overall, however, the benefits of the combination of GnRHa plus GH in cranospinal irradiation-treated children is disputed (Adan et al. 2000, Gleeson et al. 2003, Xu et al. 2003). In interpreting the results of all these studies, it should be remembered that the decision to start GnRHa therapy is partly based on the child having a poorer final height prediction, therefore by comparing the GnRHa-treated group with a group not considered for GnRHa therapy, the effect of GnRHa usage is almost certainly underestimated in all studies.
Although the numbers included in these studies are small these data support the use of combination GnRHa and $\mathrm{GH}$ in those children with radiation-induced GHD and early puberty. However further prospective randomised studies are required.

\section{Management of GHD in adolescence and adulthood}

Radiation-induced damage to the hypothalamic-pituitary axis persists into adult life and may also continue to evolve in degrees. It is therefore imperative that patients who underwent cranial irradiation in childhood are not lost to follow-up during the transition from paediatric to adult clinics. Continued surveillance of hormone status and management of hormone replacement therapy is required.

Despite the persistence of radiation-induced damage, retesting at final height should still be mandatory to identify those patients with severe GHD, who would then fulfil the criteria to receive continued GH therapy during the 'transition' period from childhood to adulthood. Reevaluation is essential because the criteria for defining GHD in childhood include all degrees of GHD and differ from those used in adulthood when only patients with severe GHD are considered for GH replacement. Pharmacological tests of $\mathrm{GH}$ status also have low reproducibility in childhood (Zadik et al. 1990, Ropelato et al. 1996) and adulthood (Vestergaard et al. 1997, Fisker et al. 1998, Hoeck et al. 1999, Van den Broeck et al. 1999) and therefore an individual testing GHD on one occasion may not do so on a subsequent occasion. Consequently, in a recently published study, only $61 \%$ of brain tumour survivors treated with $\mathrm{GH}$ during childhood retested severe GHD at final height and would therefore be suitable for consideration for further GH therapy in adult life (Gleeson et al. 2004).

\section{Transition}

A recent study determined body composition parameters in 92 young adults with childhood-onset GHD with 35 age-matched GH-naïve hypopituitary patients with adultonset GHD (Attanasio et al. 2002). Childhood-onset GHD patients had about $20 \%$ less total body mass, lean body mass, fat mass and bone mineral content than adultonset GHD patients (Attanasio et al. 2002). Furthermore, there was a significant relationship between the degree by which a child failed to achieve target height and the impairment of body composition, implying that growth as a goal in treating GHD children is of crucial importance in that it is a surrogate for normalisation of body composition in adult life. 

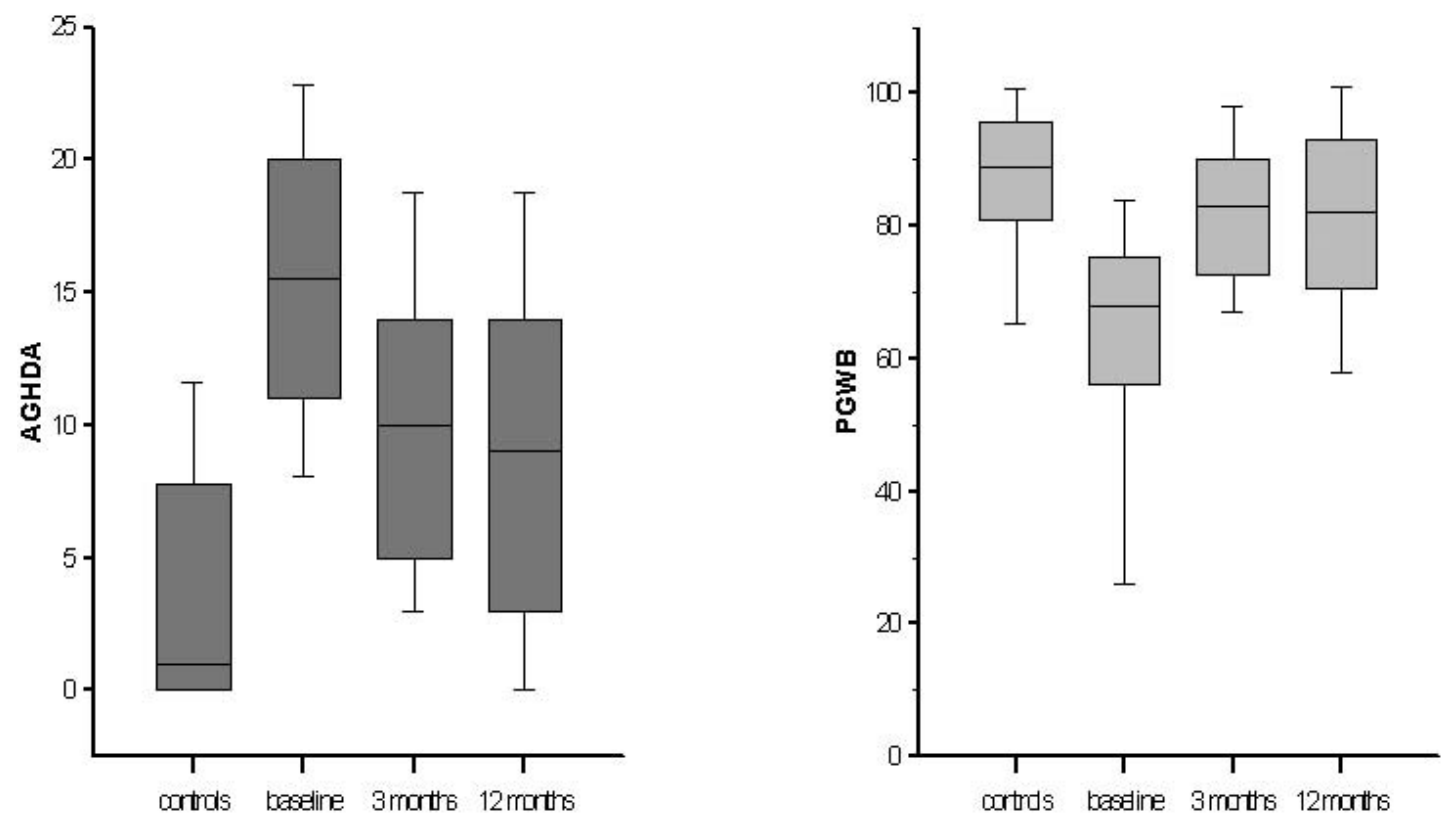

Figure 3 Box and whisker plots, representing quality of life as represented by (left plot) the AGHDA (range 0-25; high values represent greater morbidity) and (right plot) the PGWB (range 0-110; low values represent greater morbidity) in GHD survivors of childhood cancer during 12 months of GH treatment and in healthy control subjects. The lower boundary of the box indicates the 25th percentile, a line within the box marks the median, and the upper boundary of the box indicates the 75th percentile. Error bars above and below the box indicate the 90th and 10th percentiles (Murray et al. 2002). AGHDA, quality of life assessment in GHD adults; PGWB, psychological general well being schedule.

Beyond final height, several discontinuation and controlled treatment studies have suggested that by continuing GH therapy favourable body composition is maintained (Vahl et al. 2000). A multinational controlled 2-year study in patients, who had terminated GH at final height, randomised patients to GH at two different doses or no GH treatment (Shalet et al. 2003). After 2 years, significantly greater increases were seen in total bone mineral content in the GH-treated patients compared with those who were untreated (Shalet et al. 2003). The results of this study implied that withdrawal of GH replacement at final height may limit progression to peak bone mass in patients with severe childhood-onset GHD and that adequate GH replacement is required to continue this process.

Therefore, after final height has been achieved, it is now recognised that there are benefits in continuing GH replacement seamlessly in those individuals with severe GHD to achieve both adult body composition and peak bone mass amongst other end-points.

At present, only those with severe GHD are being considered for continued GH therapy in the transition period. At the same time, spontaneous GH secretion is much higher in a teenager compared with an adult, yet the criteria defining severe GHD in adults were derived from studies in middle-aged adults (Hoffman \& Ho 1994); thus it may be inappropriate to use the same threshold for diagnosing severe GHD in teenagers. This belief was highlighted recently in a study of patients with partial GHD at retesting who developed a similar deterioration in body composition as that seen in severe GHD individuals when $\mathrm{GH}$ was discontinued for 1 year after final height (Tauber et al. 2003).

\section{Adulthood}

The clinical features of adult GHD have been described over the last 13 years (de Boer et al. 1995) and the benefits of GH replacement therapy in GHD adults proven in double-blind, placebo-controlled trials (Carroll et al. 1998). These include improvement in quality of life and psychological well-being, body composition (increased lean mass and decreased fat mass), lipid profile and other cardiovascular risk factors and bone mineral density (Carroll et al. 1998). Currently, in the UK, impaired quality of life remains the major indication for a trial of $\mathrm{GH}$ replacement in adults. Young adult survivors of childhood brain tumours have many of the features that are associated with adult GHD. However, the relative contribution of GHD toward these abnormalities is difficult to disentangle from the direct effects of the primary pathology, irradiation, chemotherapy, high-dose 
glucocorticoids, insufficient exercise and excessive caloric intake.

Only one study to date has addressed the role of $\mathrm{GH}$ replacement in adult survivors of childhood cancer. Murray et al. (2002) analysed the effects of physiological $\mathrm{GH}$ replacement therapy for 12-18 months in $27 \mathrm{GHD}$ adult survivors of childhood cancer. Significant improvement in quality of life was observed (Fig. 3), but improvements in body composition, the abnormal lipid profile and bone mineral density were minor. This suggests that either GHD is not the only aetiological factor in the pathogenesis of these abnormalities or that a longer duration of $\mathrm{GH}$ replacement would be required to show benefit. Therefore, when considering the use of $\mathrm{GH}$ replacement in an adult brain tumour survivor with GHD, quality of life remains the main indication. Further studies of $\mathrm{GH}$ replacement over a longer duration are required in this cohort to assess whether, with time, other biological end-points may also be improved.

\section{Conclusions}

With the increasing numbers of childhood brain tumour survivors reaching adulthood awareness of endocrine late effects of cancer therapy is essential. These patients should be followed long term after irradiation as endocrine problems evolve over many years. These endocrinopathies may impact on quality of life, morbidity and mortality. A particularly important time is the transition from childhood to adulthood when not only is a patient most likely to be lost to follow-up but there are also important issues with regard to maturational development after final height has been achieved.

\section{References}

Acharya S, Sarafoglou K, LaQuaglia M, Lindsley S, Gerald W, Wollner N, Tan C \& Sklar C 2003 Thyroid neoplasms after therapeutic radiation for malignancies during childhood or adolescence. Cancer 97 2397-2403.

Achermann JC, Hindmarsh PC \& Brook CG 1998 The relationship between the growth hormone and insulin-like growth factor axis in long-term survivors of childhood brain tumours. Clinical Endocrinology 49 639-645.

Adan L, Sainte-Rose C, Souberbielle JC, Zucker JM, Kalifa C \& Brauner R 2000 Adult height after growth hormone $(\mathrm{GH})$ treatment for GH deficiency due to cranial irradiation. Medical Pediatric Oncology 34 14-19.

Ahmed SR, Shalet SM, Campbell RH \& Deakin DP 1983 Primary gonadal damage following treatment of brain tumors in childhood. Journal of Pediatrics 103 562-565.

Ahmed SR, Shalet SM \& Beardwell CG 1986 The effects of cranial irradiation on growth hormone secretion. Acta Paediatrica Scandinavica 75 255-260.
Albertsson-Wikland K, Lannering B, Marky I, Mellander L \& Wannholt U 1987 A longitudinal study on growth and spontaneous growth hormone $(\mathrm{GH})$ secretion in children with irradiated brain tumors. Acta Paediatrica Scandinavica $\mathbf{7 6}$ 966-973.

Anderson DM, Rennie KM, Ziegler RS, Neglia JP, Robison LR \& Gurney JG 2001 Medical and neurocognitive late effects among survivors of childhood central nervous system tumors. Cancer 92 2709-2719.

Attanasio AF, Howell S, Bates PC, Frewer P, Chipman J, Blum WF \& Shalet SM 2002 Body composition, IGF-I and IGFBP-3 concentrations as outcome measures in severely GH-deficient (GHD) patients after childhood GH treatment: a comparison with adult onset GHD patients. Journal of Clinical Endocrinology and Metabolism 87 3368-3372.

Bercu BB \& Diamond FB Jr 1986 Growth hormone neurosecretory dysfunction. Journal of Clinical Endocrinology and Metabolism 15 537-590.

Blatt J, Bercu BB, Gillin JC, Mendelson WB \& Poplack DG 1984 Reduced pulsatile growth hormone secretion in children after therapy for acute lymphoblastic leukemia. Journal of Pediatrics 104 182-186.

Bleyer WA 1999 Epidemiologic impact of children with brain tumors. Child's Nervous System 15 758-763.

de Boer H, Blok GJ \& Van der Veen EA 1995 Clinical aspects of growth hormone deficiency in adults. Endocrine Reviews 16 63-86.

Brander A, Viikinkoski P, Tuuhea J, Voutilainen L \& Kivisaari L 1992 Clinical versus ultrasound examination of the thyroid gland in common clinical practice. Journal of Clinical Ultrasound 20 37-42.

Carroll PV, Christ ER, Bengtsson BA, Carlsson L, Christiansen JS, Clemmons D, Hintz R, Ho K, Laron Z, Sizonenko P et al. 1998 Growth hormone deficiency in adulthood and the effects of growth hormone replacement: a review. Growth Hormone Research Society Scientific Committee. Journal of Clinical Endocrinology and Metabolism 83 382-395.

Chin D, Sklar C, Donahue B, Uli N, Geneiser N, Allen J, Nirenberg A, David R, Kohn B \& Oberfield SE 1997 Thyroid dysfunction as a late effect in survivors of pediatric medulloblastoma/primitive neuroectodermal tumors: a comparison of hyperfractionated versus conventional radiotherapy. Cancer $80798-804$.

Chrousos GP, Poplack D, Brown T, O'Neil D, Schwade J \& Bercu BB 1982 Effects of cranial radiation on hypothalamic-adenohypophyseal function: abnormal growth hormone secretory dynamics. Journal of Clinical Endocrinology and Metabolism 54 1135-1139.

Clarson CL \& Del Maestro RF 1999 Growth failure after treatment of pediatric brain tumors. Pediatrics 103 E37.

Clayton PE \& Shalet SM $1991 a$ The evolution of spinal growth after irradiation. Clinical Oncology 3 220-222.

Clayton PE \& Shalet SM $1991 b$ Dose dependency of time of onset of radiation-induced growth hormone deficiency. Journal of Pediatrics 118 226-228. 
Clayton PE, Shalet SM, Price DA \& Jones PH 1989 Ovarian function following chemotherapy for childhood brain tumours. Medical Pediatric Oncology 17 92-96.

Cohen P, Bright GM, Rogol AD, Kappelgaard AM \& Rosenfeld RG 2002 Effects of dose and gender on the growth and growth factor response to $\mathrm{GH}$ in GH-deficient children: implications for efficacy and safety. Journal of Clinical Endocrinology and Metabolism 87 90-98.

Constine LS, Woolf PD, Cann D, Mick G, McCormick K, Raubertas RF \& Rubin P 1993 Hypothalamic-pituitary dysfunction after radiation for brain tumors. New England Journal of Medicine 328 87-94.

Costin G 1988 Effects of low-dose cranial radiation on growth hormone secretory dynamics and hypothalamic-pituitary function. American Journal of Diseases of Children $\mathbf{1 4 2}$ $847-852$.

Crom DB, Kaste SC, Tubergen DG, Greenwald CA, Sharp GB \& Hudson MM 1997 Ultrasonography for thyroid screening after head and neck irradiation in childhood cancer survivors. Medical Pediatric Oncology 28 15-21.

Crowne EC, Wallace WH, Gibson S, Moore CM, White A \& Shalet SM 1993 Adrenocorticotrophin and cortisol secretion in children after low dose cranial irradiation. Clinical Endocrinology 39 297-305.

Darendeliler F, Livesey EA, Hindmarsh PC \& Brook CG 1990 Growth and growth hormone secretion in children following treatment of brain tumours with radiotherapy. Acta Paediatrica Scandinavica 79 950-956.

Darzy KH, Aimaretti G, Wieringa G, Gattamaneni HR, Ghigo E \& Shalet SM 2003 The usefulness of the combined growth hormone $(\mathrm{GH})$-releasing hormone and arginine stimulation test in the diagnosis of radiation-induced GH deficiency is dependent on the post-irradiation time interval. Journal of Clinical Endocrinology and Metabolism 88 95-102.

Didi M, Didcock E, Davies HA, Ogilvy-Stuart AL, Wales JK \& Shalet SM 1995 High incidence of obesity in young adults after treatment of acute lymphoblastic leukemia in childhood. Journal of Pediatrics 127 63-67.

Duffner PK, Cohen ME, Voorhess ML, MacGillivray MH, Brecher ML, Panahon A \& Gilani BB 1985 Long-term effects of cranial irradiation on endocrine function in children with brain tumors. A prospective study. Cancer 56 2189-2193.

Fisker S, Jorgensen JO \& Christiansen JS 1998 Variability in growth hormone stimulation tests. Growth Hormone and IGF Research 8 (Suppl A) 31-35.

Gleeson HK, Stoeter R, Ogilvy-Stuart AL, Gattamaneni HR, Brennan BM \& Shalet SM 2003 Improvements in final height over 25 years in growth hormone (GH)-deficient childhood survivors of brain tumors receiving $\mathrm{GH}$ replacement. Journal of Clinical Endocrinology and Metabolism 88 3682-3689.

Gleeson HK, Gattamaneni HR, Smethurst L, Brennan BM \& Shalet SM 2004 Reassessment of growth hormone status is required at final height in children treated with growth hormone replacement after radiation therapy. Journal of Clinical Endocrinology and Metabolism 89 662-666.

Gold RM, Quackenbush PM \& Kapatos G 1972 Obesity following combination of rostrolateral to $\mathrm{VMH}$ cut and contralateral mammillary area lesion. Journal of Comparative Physiology and Psychology 79 210-218.

Goldstein AM, Yuen J \& Tucker MA 1997 Second cancers after medulloblastoma: population-based results from the United States and Sweden. Cancer Causes Control 8 865-871.

Gregory J \& Reilly J 2004 Body composition and obesity. In Late Effects of Childhood Cancer, pp 155-158. Eds H Wallace \& D Green. London: Arnold.

Gurney JG, Davis S, Severson RK, Fang JY, Ross JA \& Robison LL 1996 Trends in cancer incidence among children in the U.S. Cancer 78 532-541.

Gurney JG, Ness KK, Stovall M, Wolden S, Punyko JA, Neglia JP, Mertens AC, Packer RJ, Robison LL \& Sklar CA $2003 a$ Final height and body mass index among adult survivors of childhood brain cancer: Childhood Cancer Survivor Study. Journal of Clinical Endocrinology and Metabolism $\mathbf{8 8}$ 4731-4739.

Gurney JG, Kadan-Lottick NS, Packer RJ, Neglia JP, Sklar CA, Punyko JA, Stovall M, Yasui Y, Nicholson HS, Wolden S et al. 2003 b Endocrine and cardiovascular late effects among adult survivors of childhood brain tumors: Childhood Cancer Survey Study. Cancer 97 663-673.

Healy JC, Shafford EA, Reznek RH, Webb JA, Thomas JM, Bomanji JB \& Kingston JE 1996 Sonographic abnormalities of the thyroid gland following radiotherapy in survivors of childhood Hodgkin's disease. British Journal of Radiology 69 617-623.

Heikens J, Ubbink MC, van der Pal HP, Bakker PJ, Fliers E, Smilde TJ, Kastelein JJ \& Trip MD 2000 Long term survivors of childhood brain cancer have an increased risk for cardiovascular disease. Cancer 88 2116-2121.

Helseth E, Due-Tonnessen B, Wesenberg F, Lote K \& Lundar T 1999 Posterior fossa medulloblastoma in children and young adults ( $0-19$ years): survival and performance. Child's Nervous Syststem 15 451-455 9 (Discussion 456).

Hoeck HC, Jakobsen PE, Vestergaard P, Falhof J \& Laurberg P 1999 Differences in reproducibility and peak growth hormone responses to repeated testing with various stimulators in healthy adults. Growth Hormone and IGF Research 9 18-24.

Hoffman DM \& Ho KKY 1994 Diagnosis of GH deficiency in adults. Lancet 343 1064-1068.

Kaplan MM, Garnick MB, Gelber R, Li FP, Cassady JR, Sallan SE, Fine WE \& Sack MJ 1983 Risk factors for thyroid abnormalities after neck irradiation for childhood cancer. American Journal of Medicine 74 272-280.

Lannering B \& Albertsson-Wikland K 1987 Growth hormone release in children after cranial irradiation. Hormone Research 27 13-22.

Lannering B, Jansson C, Rosberg S \& Albertsson-Wikland K 1997 Increased LH and FSH secretion after cranial irradiation in boys. Medical Pediatric Oncology 29 280-287.

Leiper AD, Stanhope R, Kitching P \& Chessells JM 1987 Precocious and premature puberty associated with treatment of acute lymphoblastic leukaemia. Archives of Diseases in Childhood 62 1107-1112.

Leong KS, Walker AB, Martin I, Wile D, Wilding J \& MacFarlane IA 2001 An audit of 500 subcutaneous glucagon stimulation tests to assess growth hormone and ACTH 
secretion in patients with hypothalamic-pituitary disease. Clinical Endocrinology 54 463-468.

Littley MD, Gibson S, White A \& Shalet SM $1989 a$ Comparison of the ACTH and cortisol responses to provocative testing with glucagon and insulin hypoglycaemia in normal subjects. Clinical Endocrinology 31 527-533.

Littley MD, Shalet SM, Beardwell CG, Robinson EL \& Sutton ML 1989b Radiation-induced hypopituitarism is dose-dependent. Clinical Endocrinology 31 363-373.

Littley MD, Shalet SM, Beardwell CG, Ahmed SR, Applegate G \& Sutton ML 1989c Hypopituitarism following external radiotherapy for pituitary tumours in adults. Quarterly Journal of Medicine 70 145-160.

Livesey EA \& Brook CG 1988 Gonadal dysfunction after treatment of intracranial tumours. Archives of Diseases in Childhood 63 495-500.

Livesey EA \& Brook CG 1989 Thyroid dysfunction after radiotherapy and chemotherapy of brain tumours. Archives of Diseases in Childhood 64 593-595.

Livesey EA, Hindmarsh PC, Brook CG, Whitton AC, Bloom HJ, Tobias JS, Godlee JN \& Britton J 1990 Endocrine disorders following treatment of childhood brain tumours. British Journal of Cancer 61 622-625.

Lustig RH, Post SR, Srivannaboon K, Rose SR, Danish RK, Burghen GA, Xiong X, Wu S \& Merchant TE 2003a Risk factors for the development of obesity in children surviving brain tumors. Journal of Clinical Endocrinology and Metabolism 88 611-616.

Lustig RH, Hinds PS, Ringwald-Smith K, Christensen RK, Kaste SC, Schreiber RE, Rai SN, Lensing SY, Wu S $\&$ Xiong X $2003 b$ Octreotide therapy of pediatric hypothalamic obesity: a double-blind, placebo-controlled trial. Journal of Clinical Endocrinology and Metabolism $\mathbf{8 8}$ 2586-2592.

Mericq V, Gajardo H, Eggers M, Avila A \& Cassorla F 2002 Effects of treatment with $\mathrm{GH}$ alone or in combination with LHRH analog on bone mineral density in pubertal GH-deficient patients. Journal of Clinical Endocrinology and Metabolism 87 84-89.

Moshang T Jr, Rundle AC, Graves DA, Nickas J, Johanson A \& Meadows A 1996 Brain tumor recurrence in children treated with growth hormone: the National Cooperative Growth Study experience. Journal of Pediatrics 128 S4-S7.

Mul D, Wit JM, Oostdijk W \& Van den Broeck J 2001 The effect of pubertal delay by GnRH agonist in GH-deficient children on final height. Journal of Clinical Endocrinology and Metabolism 86 4655-4656.

Murray RD, Darzy KH, Gleeson HK \& Shalet SM 2002 GH-deficient survivors of childhood cancer: GH replacement during adult life. Journal of Clinical Endocrinology and Metabolism 87 129-135.

Nivot S, Benelli C, Clot JP, Saucet C, Adan L, Souberbielle JC, Zucker JM, Rappaport R \& Brauner R 1994 Nonparallel changes of growth hormone $(\mathrm{GH})$ and insulin-like growth factor-I, insulin-like growth factor binding protein-3, and GH-binding protein, after craniospinal irradiation and chemotherapy. Journal of Clinical Endocrinology and Metabolism 78 597-601.
Noorda EM, Somers R, van Leeuwen FE, Vulsma T \& Behrendt H 2001 Adult height and age at menarche in childhood cancer survivors. European Journal of Cancer 37 605-612.

de Nully Brown P, Olsen JH, Hertz H, Carstensen B \& Bautz A 1995 Trends in survival after childhood cancer in Denmark, 1943-1987: a population-based study. Acta Paediatrica 84 316-324.

Oberfield SE, Sklar C, Allen J, Walker R, Mcelwain M, Papadakis V \& Maenza J 1992 Thyroid and gonadal function and growth of long-term survivors of medulloblastoma/PNET. In Late Effects of Treatment for Childhood Cancer, pp 55-62. Eds DM Green \& GJ D'Angio. New York: Wiley-Liss, Inc.

Oberfield SE, Nirenberg A, Allen JC, Cohen H, Donahue B, Prasad V, Schiff R, Pang S, Ghavimi F, David R et al. 1997 Hypothalamic-pituitary-adrenal function following cranial irradiation. Hormone Research 47 9-16.

Ogilvy-Stuart AL \& Shalet SM 1995 Growth and puberty after growth hormone treatment after irradiation for brain tumours. Archives of Diseases in Childhood 73 141-146.

Ogilvy-Stuart AL, Shalet SM \& Gattamaneni HR 1991 Thyroid function after treatment of brain tumors in children. Journal of Pediatrics 119 733-737.

Ogilvy-Stuart AL, Clayton PE \& Shalet SM 1994 Cranial irradiation and early puberty. Journal of Clinical Endocrinology and Metabolism 78 1282-1286.

Olshan JS, Gubernick J, Packer RJ, D'Angio GJ, Goldwein JW, Willi SM \& Moshang T Jr 1992 The effects of adjuvant chemotherapy on growth in children with medulloblastoma. Cancer 70 2013-2017.

Orme SM, Peacey SR, Barth JH \& Belchetz PE 1996 Comparison of tests of stress-released cortisol secretion in pituitary disease (see comments). Clinical Endocrinology 45 135-140.

Packer RJ, Boyett JM, Janss AJ, Stavrou T, Kun L, Wisoff J, Russo C, Geyer R, Phillips P, Kieran M et al. 2001 Growth hormone replacement therapy in children with medulloblastoma: use and effect on tumor control. Journal of Clinical Oncology 19 480-487.

Partsch CJ \& Sippell WG 2002 Treatment of central precocious puberty. Best Practice Research in Clinical Endocrinology and Metabolism 16 165-189.

Paulino AC 2002 Hypothyroidism in children with medulloblastoma: a comparison of 3600 and $2340 \mathrm{cGy}$ craniospinal radiotherapy. International Journal of Radiation Oncology-Biology-Physics 53 543-547.

Probert JC, Parker BR \& Kaplan HS 1973 Growth retardation in children after megavoltage irradiation of the spine. Cancer 32 634-639.

Rappaport R, Brauner R, Czernichow P, Thibaud E, Renier D, Zucker JM \& Lemerle J 1982 Effect of hypothalamic and pituitary irradiation on pubertal development in children with cranial tumors. Journal of Clinical Endocrinology and Metabolism 54 1164-1168

Reilly JJ, Ventham JC, Ralston JM, Donaldson M \& Gibson B 1998 Reduced energy expenditure in preobese children treated for acute lymphoblastic leukemia. Pediatric Research $\mathbf{4 4}$ $557-562$.

Ricardi U, Corrias A, Einaudi S, Genitori L, Sandri A, di Montezemolo LC, Besenzon L, Madon E \& Urgesi A 2001 
Thyroid dysfunction as a late effect in childhood medulloblastoma: a comparison of hyperfractionated versus conventionally fractionated craniospinal radiotherapy. International Journal of Radiation Oncology-Biology-Physics 50 1287-1294.

Ries LAG, Eisner MP, Kosary CL, Hankey BF, Miller BA, Clegg L Mariotto A, Fay MP, Feuer EJ, Edwards BK 2003 SEER Cancer Statistics Review, 1975-2000. Bethesda: National Cancer Institute. Available at: http://seer.cancer.gov/.

Ron E, Lubin JH, Shore RE, Mabuchi K, Modan B, Pottern LM, Schneider AB, Tucker MA \& Boice JD Jr 1995 Thyroid cancer after exposure to external radiation: a pooled analysis of seven studies. Radiation Research 141 259-277.

Ropelato MG, Martinez A, Heinrich JJ \& Bergada C 1996 Reproducibility and comparison of growth hormone secretion tests. Journal of Pediatrics and Endocrinology and Metabolism 9 41-50.

Rose SR, Lustig RH, Pitukcheewanont P, Broome DC, Burghen GA, Li H, Hudson MM, Kun LE \& Heideman RL 1999 Diagnosis of hidden central hypothyroidism in survivors of childhood cancer. Journal of Clinical Endocrinology and Metabolism 84 4472-4479.

Roth C, Schmidberger H, Schaper O, Leonhardt S, Lakomek M, Wuttke W \& Jarry H 2000 Cranial irradiation of female rats causes dose-dependent and age-dependent activation or inhibition of pubertal development. Pediatric Research 47 586-591.

Roth C, Lakomek M, Schmidberger H \& Jarry H 2001 (Cranial irradiation induces premature activation of the gonadotropinreleasing-hormone). Klinische Padiatrie 213 239-243.

Saggese G, Federico G, Barsanti S \& Fiore L 2001 The effect of administering gonadotropin-releasing hormone agonist with recombinant-human growth hormone $(\mathrm{GH})$ on the final height of girls with isolated GH deficiency: results from a controlled study. Journal of Clinical Endocrinology and Metabolism 86 1900-1904.

Salomon F, Cuneo RC, Hesp R \& Sonksen PH 1989 The effects of treatment with recombinant human growth hormone on body composition and metabolism in adults with growth hormone deficiency. New England Journal of Medicine 321 1797-1803.

Samaan NA, Bakdash MM, Caderao JB, Cangir A, Jesse RH Jr \& Ballantyne AJ 1975 Hypopituitarism after external irradiation. Evidence for both hypothalamic and pituitary origin. Annals of Internal Medicine 83 771-777.

Samaan NA, Vieto R, Schultz PN, Maor M, Meoz RT, Sampiere VA, Cangir A, Ried HL \& Jesse RH Jr 1982 Hypothalamic, pituitary and thyroid dysfunction after radiotherapy to the head and neck. International Journal of Radiation OncologyBiology-Physics 8 1857-1867.

van Santen HM, Vulsma T, Dijkgraaf MG, Blumer RM, Heinen R, Jaspers MW, Geenen MM, Offringa MO, de Vijlder JJ \& van den Bos C 2003 No damaging effect of chemotherapy in addition to radiotherapy on the thyroid axis in young adult survivors of childhood cancer. Journal of Clinical Endocrinology and Metabolism 88 3657-3663.

Schmiegelow M, Lassen S, Poulsen HS, Feldt-Rasmussen U, Schmiegelow K, Hertz H \& Muller J 2000 Cranial radiotherapy of childhood brain tumours: growth hormone deficiency and its relation to the biological effective dose of irradiation in a large population based study. Clinical Endocrinology 53 191-197.

Schmiegelow M, Lassen S, Poulsen HS, Schmiegelow K, Hertz H, Andersson AM, Skakkebaek NE \& Muller J 2001 Gonadal status in male survivors following childhood brain tumors. Journal of Clinical Endocrinology and Metabolism $\mathbf{8 6}$ 2446-2452.

Schmiegelow M, Feldt-Rasmussen U, Rasmussen AK, Poulsen HS \& Muller J 2003a A population-based study of thyroid function after radiotherapy and chemotherapy for a childhood brain tumor. Journal of Clinical Endocrinology and Metabolism 88 136-140.

Schmiegelow M, Feldt-Rasmussen U, Rasmussen AK, Lange M, Poulsen HS \& Muller J 2003b Assessment of the hypothalamo-pituitary-adrenal axis in patients treated with radiotherapy and chemotherapy for childhood brain tumor. Journal of Clinical Endocrinology and Metabolism $\mathbf{8 8}$ 3149-3154

Schneider AB, Recant W, Pinsky SM, Ryo UY, Bekerman C \& Shore-Freedman E 1986 Radiation-induced thyroid carcinoma. Clinical course and results of therapy in 296 patients. Annals of Internal Medicine 105 405-412.

Schneider AB, Ron E, Lubin J, Stovall M \& Gierlowski TC 1993 Dose-response relationships for radiation-induced thyroid cancer and thyroid nodules: evidence for the prolonged effects of radiation on the thyroid. Journal of Clinical Endocrinology and Metabolism 77 362-369.

Schwartz MW, Woods SC, Porte D Jr, Seeley RJ \& Baskin DG 2000 Central nervous system control of food intake. Nature 404 661-671.

Shalet SM, Beardwell CG, Morris-Jones PH \& Pearson D 1975 Pituitary function after treatment of intracranial tumours in children. Lancet ii 104-107.

Shalet SM, Beardwell CG, Pearson D \& Jones PH 1976a The effect of varying doses of cerebral irradiation on growth hormone production in childhood. Clinical Endocrinology 5 287-290.

Shalet SM, Beardwell CG, Jones PH \& Pearson D $1976 b$ Growth hormone deficiency after treatment of acute leukaemia in children. Archives of Diseases in Childhood 51 489-493.

Shalet SM, Beardwell CG, MacFarlane IA, Jones PH \& Pearson D 1977 Endocrine morbidity in adults treated with cerebral irradiation for brain tumours during childhood. Acta Endocrinologica 84 673-680.

Shalet SM, Gibson B, Swindell R \& Pearson D 1987 Effect of spinal irradiation on growth. Archives of Diseases in Childhood 62 461-464.

Shalet SM, Shavrikova E, Cromer M, Child CJ, Keller E, Zapletalova J, Moshang T, Blum WF, Chipman JJ, Quigley CA et al. 2003 Effect of growth hormone (GH) treatment on bone in post-pubertal GH deficient (GHD) patients: a 2-year randomized, controlled, dose-ranging study. Journal of Clinical Endocrinology and Metabolism 88 4124-4129.

Sklar C, Whitton J, Mertens A, Stovall M, Green D, Marina N, Greffe B, Wolden S \& Robison LL 2000 Abnormalities of the thyroid in survivors of Hodgkin's disease: data from the Childhood Cancer Survivor Study. Journal of Clinical Endocrinology and Metabolism 85 3227-3232. 
Sklar CA, Mertens AC, Mitby P, Occhiogrosso G, Qin J, Heller G, Yasui Y \& Robison LL 2002 Risk of disease recurrence and second neoplasms in survivors of childhood cancer treated with growth hormone: a report from the Childhood Cancer Survivor Study. Journal of Clinical Endocrinology and Metabolism 87 3136-3141.

Spoudeas HA, Hindmarsh PC, Matthews DR \& Brook CG 1996 Evolution of growth hormone neurosecretory disturbance after cranial irradiation for childhood brain tumours: a prospective study. Journal of Endocrinology 150 329-342.

Spoudeas HA, Charmandari E \& Brook CG 2003 Hypothalamopituitary-adrenal axis integrity after cranial irradiation for childhood posterior fossa tumours. Medical Pediatric Oncology 40 224-229.

Sulmont V, Brauner R, Fontoura M \& Rappaport R 1990 Response to growth hormone treatment and final height after cranial or craniospinal irradiation. Acta Paediatrica Scandinavica 79 542-549.

Swerdlow AJ, Reddingius RE, Higgins CD, Spoudeas HA, Phipps K, Qiao Z, Ryder WD, Brada M, Hayward RD, Brook CG et al. 2000 Growth hormone treatment of children with brain tumors and risk of tumor recurrence. Journal of Clinical Endocrinology and Metabolism 85 4444-4449.

Tataranni PA, Larson DE, Snitker S, Young JB, Flatt JP \& Ravussin E 1996 Effects of glucocorticoids on energy metabolism and food intake in humans. American Journal of Physiology 271 E317-E325.

Tauber M, Jouret B, Cartault A, Lounis N, Gayrard M, Marcouyeux C, Pienkowski C, Oliver I, Moulin P, Otal P et al. 2003 Adolescents with partial growth hormone (GH) deficiency develop alterations of body composition after $\mathrm{GH}$ discontinuation and require follow-up. Journal of Clinical Endocrinology and Metabolism 88 5101-5106.

Tucker MA, Jones PH, Boice JD Jr, Robison LL, Stone BJ, Stovall M, Jenkin RD, Lubin JH, Baum ES, Siegel SE et al.
1991 Therapeutic radiation at a young age is linked to secondary thyroid cancer. The Late Effects Study Group. Cancer Research 51 2885-2888.

Vahl N, Juul A, Jorgensen JO, Orskov H, Skakkebaek NE \& Christiansen JS 2000 Continuation of growth hormone (GH) replacement in GH-deficient patients during transition from childhood to adulthood: a two-year placebo-controlled study. Journal of Clinical Endocrinology and Metabolism $\mathbf{8 5}$ 1874-1881.

Van den Broeck J, Hering P, Van de Lely A \& Hokken-Koelega A 1999 Interpretative difficulties with growth hormone provocative retesting in childhood-onset growth hormone deficiency. Hormone Research 51 1-9.

Van Dongen-Melman JE, Hokken-Koelega AC, Hahlen K, De Groot A, Tromp CG \& Egeler RM 1995 Obesity after successful treatment of acute lymphoblastic leukemia in childhood. Pediatric Research 38 86-90.

Vestergaard P, Hoeck HC, Jakobsen PE \& Laurberg P 1997 Reproducibility of growth hormone and cortisol responses to the insulin tolerance test and the short ACTH test in normal adults. Hormone and Metabolic Research 9 $106-110$.

Warner JT, Bell W, Webb DK \& Gregory JW 1998 Daily energy expenditure and physical activity in survivors of childhood malignancy. Pediatric Research 43 607-613.

Xu W, Janss A \& Moshang T 2003 Adult height and adult sitting height in childhood medulloblastoma survivors. Journal of Clinical Endocrinology and Metabolism $\mathbf{8 8}$ 4677-4681.

Zadik Z, Chalew SA, Gilula Z \& Kowarski AA 1990 Reproducibility of growth hormone testing procedures: a comparison between 24-hour integrated concentration and pharmacological stimulation. Journal of Clinical Endocrinology and Metabolism 71 1127-1130. 